\title{
SOFT SWITCHING TECHNIQUE USING RESONANT CONVERTER FOR CONSTANT SPEED DRIVE
}

\author{
Sukhi . $Y^{1}$ and Padmanabhan. $S^{2}$ \\ ${ }^{1}$ Research Scholar,Sathyabama University, Rajiv Gandi Road, Tamilnadu, India. \\ 2Department of Electroncis and Communication Engg., AMA Engineering College, Kancheepuram, Tamilnadu, India. \\ E-mail : 'sukirmk03@yahoo.com
}

\begin{abstract}
Azero voltage switched pulse width modulated series parallel resonant converter is presented in this paper. The performance of the converter for constant output voltage with the application of constant switching frequency but variable pulse width is analyzed. The converter operation is applied for motor load applications, where the load varies widely but the output voltage is fixed and is well regulated. Hence the speed of the motor is maintained constant.Experi-mental results are obtained to verify the theoretical results.
\end{abstract}

Key words: Zero Voltage Switching, Zero Current switching, DC-DC Converter, Resonant Converter, Soft Switching.

\section{INTRODUCTION}

The series parallel resonant converter is a preferred topology for dc-dc power conversion. Its main attractive features are zero voltage turn on switching (ZVS), constant switching frequency and simple control similar to that of hard switched full bridge PWM converter. Resonant dc-do converters are particularly used where high switching frequency are needed to minimize reactive component size since by operating the converters above the resonant tank natural frequency, lossless switching conditions may be achieved[1]. The series parable converter is a particularly attractive topology since it combines a wide operating range with modest component rating. Operation of resonant converter above resonance (lagging power factor mode) results in a number of advantages. They are elimination of di/dt inductors and lossy snubbers, use of slow recovery diodes internal to MOSFET's reduced size of magnetic components etc[2]. The major limitation of high peak reverse voltage developed across the devices can be overcome by incorporating anti parable diodes across each diode. The inverse diode associated with the device is sufficient to operate the circuit at hundreds of kilohertz, which allows to a use a diode having low turn off time. The frequency of operation is chosen to obtain the desired power handling capacity.

The voltage or current in the resonant components becomes maximum at the resonant frequency and by altering the frequency around the frequency point, the voltage on the resonant frequencies can be adjusted to any desired value. By rectifying the voltage across the capacitor, a dc voltage is obtained which may be filtered to achieve which may be filtered to achieve smooth dc. This $\mathrm{dc}$ voltage can either be lower or higher than the dc supply voltage. Thus this can be operated as a step up or step dower converter and since the output is taken through a high a high frequency transformer, the output voltage can be transformed to any desired value. Good efficiency should be maintained at lower loads and to achieve this, the peak current should decrease with decrease of load proportionately. During the calculation of copper loss, skin consideration because this is very pronounced at high operating frequency. The device losses are important factor and a clear estimate of the losses, not only of the semiconductor device but also of the magnetic circuits should be made to arrive at the optimum design value[3]. The efficiency becomes maximum when the operating frequency is close to the resonant frequency. But as the operating frequency approaches the resonant frequency, the time period consisting of the conduction period of anti parallel diodes across the incoming switches and the fall time of the outgoing switches become less.

\section{ANALYSIS AND MODELLING}

The load current $I_{0}$ is considered constant since a large inductor $\left(L_{0}>>L_{s}\right)$ is assumed at the output circuit. Consequently the current to the input bridge rectifier $i_{b}(t)$ has constant amplitude $+\mathrm{I}_{0}$ or $-\mathrm{I}_{0}$ depending on whether the voltage $V_{C P}(t)$ is +ve or -ve respectively. Hence the output circuit can be represented as constant current sink $\mathrm{ql}_{0}$, where $q=+1$ when $V_{c p}(t)$ is $=+$ otherwise $q=-1$. The switching frequency is constant and power control is obtained by phase shifting the gating signals to vary the pulse width . The converter is designed to operate with maximum pulse width $(\delta=\pi)$.

When load current is maximum and supply voltage is minimum, a square wave voltage is impressed across the terminal $A B$. The phase signal $\Phi$ between the gating signals is control to regulate the load voltage with variation with the load current or the input supply voltage. As the load current decreases to regulate output voltage the pulse width is decreased by phase shifting the getting 
signals $G_{2}$ and $G_{4}$ respectively with respect to $G_{1}$ and $G_{3}$ as shown in figure. It must be noted that gating signal $G_{1}$ and $G_{3}$ (also $G_{2}$ and $G_{4}$ ) are always $180^{\circ}$ out of phase. The voltage across the terminal $A B, V_{A B}$ depends upon the switching status of the switches. When the gating signal $G$, is present then $V_{A B}(t)=+E_{\text {in }}$ if $G_{2}$ also present, otherwise $=0$.Similarly $V_{A B}(t)=-E_{\text {in }}$ or 0 depending on switching status of $\mathrm{G}_{3}$ and $\mathrm{G}_{4}$.

The series parallel converter is a combination of a series and a parallel capacitor load converter. This combined topology eliminates the weak points of both. The main disadvantage of the series loaded circuit is that it cannot be regulated at no load, while in the parallel circuit a circulating current flows irrespective of load current. The circuit configuration is shown in Fig.1.The circuit inductor $L_{s}$ and capacitor $C_{s}$ forms the resonant circuit.

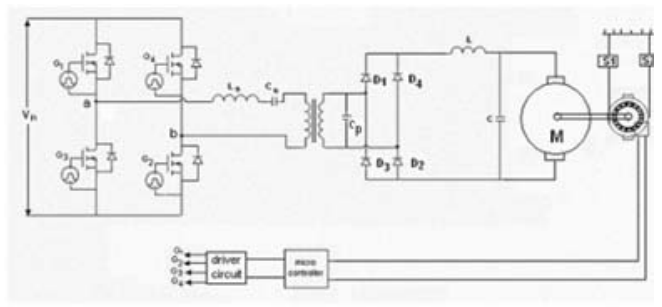

Fig.1 Basic Circuit Diagram With Feedback

The load is taken from the capacitor $\mathrm{Cp}$ through a transformer $\mathrm{T}$, the voltage of which is rectified and filtered as shown in Fig 1. The input voltage $\mathrm{V}$ ' to the resonant circuit is taken as of the square wave voltage $V_{A B}$. The analysis of the series parallel resonant converter is made at a frequency greater than resonant frequency.

\section{PRINCIPLE OF OPERATION}

In this analysis, the equivalent reactance across $A B$ is inductive. In this mode switching frequency is more than series resonant frequency and equivalent reactance is inductive across the terminal $A B$. The converter operates at lagging power factor (above resonance) mode.Fig.2 shows typical waveforms for this mode of operation. It is evident from the figure that diodes $D_{1} \& D_{2}$ are conducting initially at $t=t_{0}$. When the current through the diode reaches $\left(t=t_{1}\right)$, switch $S_{1} \& S_{2}$ are tuned on and currents transferred from the anti-parallel diodes. The converter operates till $t=t_{2}$. There is no voltage across the switches at turn on (since $D_{1} \& D_{2}$ are conducting) which eliminates turn on losses and facilitates operation of switches with loss less snubbers. At $t=t_{2}$, the transition from interval 1 to interval 2 takes place. $A t t=t_{3}$ i.e. $\left(t_{0}+T / 2\right)$ when switches $S_{1} \& S_{2}$ are turned off, the current is transformed to $D_{3} \& D_{4}$
Turn off losses is present in such type of operation because during turn off, current and voltage are simultaneously present at the switch. The sequence of events repeats in the next half cycle. Interval $t_{0}-t_{1} \& t_{3}-t_{4}$ are called regenerative interval and $t_{1}-t_{3} \& t_{4}-t_{5}$ are power interval.

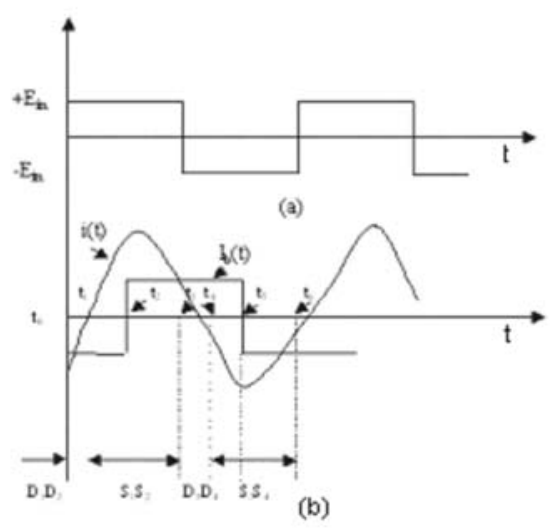

Fig. 2 Typical Waveform $(a) V_{A B}(t)(b) I_{b}(t)$ and $i(t)$

\section{MATHEMATICAL ANALYSIS OF CONVERTER}

Following assumption are used in the analysis of the series - parallel resonant converter.

a. (a)The switches, diodes, inductors, capacitors and snubber components used are ideal.

b. (b)The effects of snubber are neglected.

c. (c)The inductance $I_{0}$ is large enough to keep the load current constant.

d. (d)The high frequency transformer is ideal and has unity turns ratio.

Fig.3 represents the output circuit of bridge rectifier to the resonant converter. $V_{c 0}$ and $I_{b}$ represent the rms fundamental component of $V_{c p}(t)$ and $I_{b}(t)$ respectively. The input voltage to the bridge rectifier is also assumed to be sinusoidal.

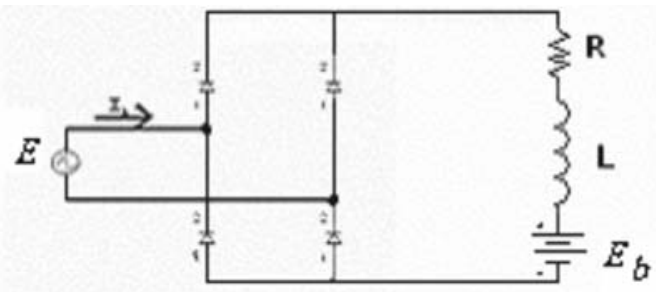

Fig.3 Output Circuit of Bridge Rectifier to the Resonant Converter

The motor load consists of a resistance $R$, inductance $L$ and back emf $E_{b}$ The load current no longer assumes the waveform of the load voltage but can be derived from the 
following differential equation for the circuit diagram of Fig.3.The instantaneous current will be guided by the differential equation.

$$
L \frac{d i}{d t}+R i=\sqrt{2} E \sin \left(\omega t+\theta_{1}\right)-E_{b}
$$

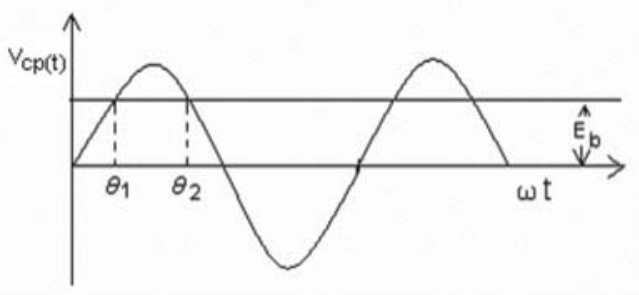

Fig 4. Voltage Waveform Across The Parallel Capacitor

From fig. 4 the conduction angle of diodes is limited between the angle $\theta_{1}$ and $\theta_{2}$ It cannot be less than $\theta_{1}$ and more than $\theta_{2}$ because the diodes cannot conduct in these cases because its anode voltage is more negative than the cathode voltage. The solution of Eq.1 may be written as a sum of two parts, the steady state $\mathrm{i}_{\mathrm{s}}$ and the transient $\mathrm{i}_{\mathrm{t}}$.

$$
\begin{aligned}
& i_{s}=\frac{\sqrt{2} E}{Z} \sin \left(\omega t+\theta_{1}\right)-\frac{E_{b}}{R_{L}} \\
& i_{t}=C_{1} \exp ^{-\omega t / \tan \phi} \\
& \text { Where } \\
& \quad Z=\left(R^{2}+\omega^{2} L^{2}\right)^{1 / 2}
\end{aligned}
$$

and

$$
\tan \phi=\frac{\omega L}{R}
$$

Total current

$$
\begin{aligned}
& i=i_{s}+i_{t} \\
& i=\frac{\sqrt{2} E}{Z} \sin \left(\omega t+\theta_{1}-\phi\right)-\frac{E_{b}}{R_{L}}+C_{1} e^{-\omega t / \tan \phi}
\end{aligned}
$$

Average load voltage

$$
\begin{aligned}
& V_{c}=E_{b}+I_{C} R_{L} \\
& V_{c}=E_{b}\left(1-\frac{\theta}{\pi}\right)+\frac{2 \sqrt{2} E}{\pi} \sin \frac{\theta}{2} \sin \left(\theta_{1}+\frac{\theta}{2}\right)
\end{aligned}
$$

The rms voltage across the load impedance only is

$$
\begin{aligned}
& V_{\text {Lmss }}=\left[\frac{1}{\pi} \int_{0}^{\theta}\left(2 E^{2} \sin ^{2}\left(\omega t+\theta_{1}\right)-E_{b}^{2}\right) l(\omega t)\right]^{1 / 2} \\
& V_{L m s s}=\left[\frac{\theta}{\pi}\left(E^{2}-E_{b}^{2}\right)-\frac{E^{2}}{2 \pi}\left(\sin 2\left(\theta+\theta_{1}\right)-\sin 2 \theta_{1}\right)\right]^{1 / 2}
\end{aligned}
$$

Therefore the total rms load voltage including the battery is

$$
\begin{aligned}
V_{c r m s} & =\left[V_{\text {Lrms }}^{2}+E_{b}^{2}\right]^{/ 2} \\
V_{\text {crms }} & =\left[E^{2} \frac{\theta}{\pi}+E_{b}^{2}\left(1-\frac{\theta}{\pi}\right)-\frac{E^{2}}{2 \pi}\left(\sin 2\left(\theta+\theta_{1}\right)-\sin 2 \theta_{1}\right)\right]
\end{aligned}
$$

The RMS fundamental voltage across $\mathrm{Cp}$ is given by

$$
V_{c p}=\frac{2 \sqrt{2} E_{i n} \sin \delta / 2}{\pi \times\left[\left(\frac{m+1}{m}\right)\left(1-y^{2}\right)+\frac{8}{\pi^{2}} j Q\left(y-\frac{1}{(m+1) y}\right)\right.}
$$

he ratio of output voltage to input voltage is given by

$$
\frac{E_{0}}{E_{i}}=\frac{\sin \delta / 2}{\frac{\pi^{2}}{8}\left(\frac{m+1}{m}\right)\left(1-y^{2}\right)+j Q\left(y-\frac{1}{(m+1) y}\right.}
$$

The R.M.S. fundamental Voltage across $\mathrm{AB}$ is given by

$$
V_{a b}=\frac{2 \sqrt{2} E_{i n} \sin \delta / 2}{\pi}
$$

The current through the inductor is

$$
I=\frac{V_{a b}}{Z_{e q}}
$$

The peak voltage across the series capacitor is

$$
V_{c s p}=\sqrt{2} * I * X_{c s}
$$

\section{PERFORMANCE CHARACTERISTICS}

In designing the full bridge series-parallel resonant converter, the given data would be the input and output voltage, output current and possibly the desired switching frequency. All other parameters of the converter need to be determined. The variable most important from the design point of view is normalized converter gain $\left(E_{0} /\right.$ Ein), normalized switching frequencies y, peak inductor current $\left(i_{i s}\right)$ peak series capacitor voltage $V_{c s}$. peak parallel capacitor voltage $V_{c p}$ etc, because they provide information to determine the component ratings. Since the graphs gives more useful information then equations in understanding and designing a system, the analysis present is used to obtain the design curves in this section.

A. Variation of converter gain $\left(E_{d} / E_{i n}\right)$ vs normalized switching frequency (y)

A set of characteristics have been plotted showing the variation of normalized switching frequency with $Q$ as a parameter. Fig. 5 shows one such that in which the curves have been plotted for various values of $Q$ from 1 to 6 for $\mathrm{m}=\mathrm{Cs} / \mathrm{cp}=1$. The curves show that normalized converter gain for a given $Q$ increases first, reaches a maximum and then decreases as normalized switching frequency increased from .3 to 1.5 . 
For higher values of $Q$, the normalized gain is maximum near the series resonant frequency $=1 / 2 \pi$ $\left(L_{s} C_{s}\right)^{1 / 2}, C s=\omega o /(m+1)^{1 / 2}$ i.e. at normalized switching $y=$ 0. 707. At lower values of $Q$, the peak of curves occurs at the frequency more than series resonant frequency i.e. load resistance is sufficiently small for high values of $Q$ to shunt the parallel capacitor and nullify its effect on the performance.

At light load, $Q$ decreases and the effect of $C p$ comes in to play and as a result resonant peak moves towards higher frequency. This is because the equivalent capacitance is given by parallel combination of $\mathrm{C}_{s} \& \mathrm{C}_{p}$. At sufficient light load or no load the resonant peak occurs at $f=1 / 2 \pi(\mathrm{LCsCp} / \mathrm{Cs}+\mathrm{Cp})^{1 / 2}$ i.e. at normalized switching frequency $y=1.0$.

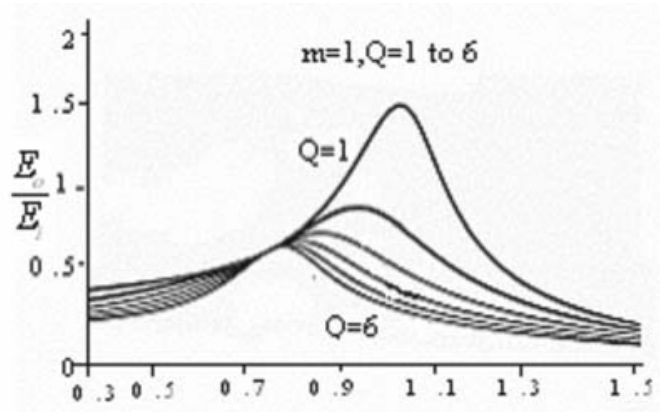

Fig.5 Variation of Voltage Gain Versus Normalized Switching Frequency for Various Values of $Q$ with $m=1$

\section{B. Selection of normalized switching frequency}

The output voltage regulated at all load by proper selection of $y$. In Fig. 5 for $y=0.75$ the output voltage can be regulated at $E_{0} / E_{\text {in }}=0.8$ for the variation in $Q$ up to 6. But at $y=0.8$, the output voltage can be maintained at this value of only up to $Q=5$. As y increases further, the range of $Q$ up to which the converter can be regulated decreases. This implies that too high value of $y$ cannot be chosen especially when wide load variations are expected. Besides y should not be of low value. Otherwise operation above resonance may not possible keeping these two factors in mind $y=0.8$ have been chosen. It can be seen from Fig.5 that for variation in $Q$ up to $5, E_{0} / E_{m}=0.8$ can be maintained.

\section{DESIGN PROCEDURE}

The output current is rectified and averaged tank current is reflected to the secondary side of the transformer. Since the tank current is directly related to the output current, therefore we should choose a large conversion ratio, so that the turns ratio is minimized, resulting in the smallest possible tank current on the primary for a specified output current on the secondary.
Hence the conversion ratio should be chosen close to one. Based on above consideration, the following optimum values are selected in the design of the converter.

Normalized frequency $y=0.8$

$\mathrm{Cs} / \mathrm{Cp}$ ratio $\mathrm{m}=1$

$Q$ of tank circuit at full load $=5$

\section{A.Design Example}

Input voltage $E_{\text {in }}=30$ volts

Output voltage $E_{0}=24$ volts

Output Current $=1.5 \mathrm{Amps}$

Switching frequency $=50 \mathrm{kHz}$

$m=C_{s} / C_{p}=1, Q=5, y=0.8$

Load resistance $=\mathrm{V}_{0} I_{0}=16 \Omega$

$$
\begin{aligned}
& R=\frac{\omega_{0} L}{Q}=\frac{1}{Q} \times \sqrt{\frac{L}{C}} \\
& \sqrt{\frac{L}{C}}=Q \times R=5 \times 16=80
\end{aligned}
$$

Resonant frequency $\mathrm{f}_{0}$ is given by

$$
\begin{aligned}
& f_{0}=f / y=50,000 / 0.8=62.5 \mathrm{kHz} \text { But } \\
& f_{0}=\frac{1}{2 \pi \sqrt{L C}} \\
& \frac{1}{\sqrt{L C}}=2 \pi \times 62.5 \times 10^{3}
\end{aligned}
$$

The values of $L \& C$ are $L=204 \mu \mathrm{H}$

$C=0.0318 \mu \mathrm{F}$

Since $C s=C p, C s=C p=2 C=0.0636 \mu \mathrm{F}$

\section{EXPERIMENTAL RESULTS}

Some testing results are presented in this section to verify the theoretical predictions of previous sections. An experimental prototype has been implemented for a motor load. The load rating is $24 \mathrm{~V}, 36 \mathrm{~W}$ and $4000 \mathrm{rpm}$ motor. The resonant inductor is $0.261 \mathrm{mH}$ and the inductor is wound around ferrite core and the series resonant capacitor is $0.47 \mathrm{uF}$ and the capacitor used is of polypropylene film type. The switching frequency is $50 \mathrm{KHz}$.All the four switches used is of IRF460 with an external fast recovery diode BYE26E connected across each switching device. In the secondary side, the diodes used for rectification are FR306. The filter inductor is $0.1 \mathrm{uH}$ and is wound around ferrite core. The filter capacitance is $1000 \mathrm{uF}, 63 \mathrm{~V}$ and the capacitor used is of electrolytic type.Fig. 6 to Fig. 8 shows the experimental output obtained. In each figure,(a) shows 
the voltage across the series capacitor and (b) shows the output voltage across the load after connecting the filter elements.

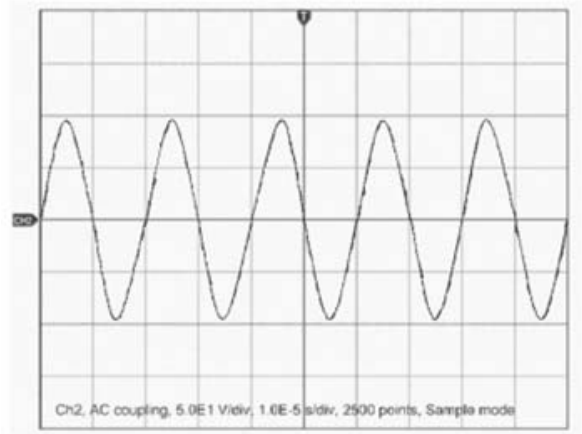

(a)

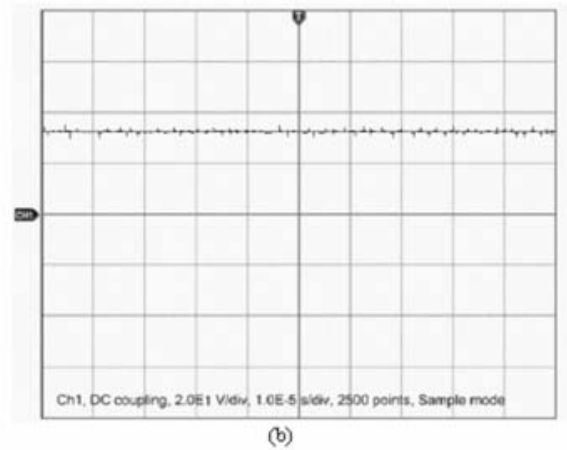

Fig.6 Experimental Results for Series Parallel Resonant Converter at full load with $m=1$ : (a) $V_{c s}$, (b) $V_{0}$ with filter
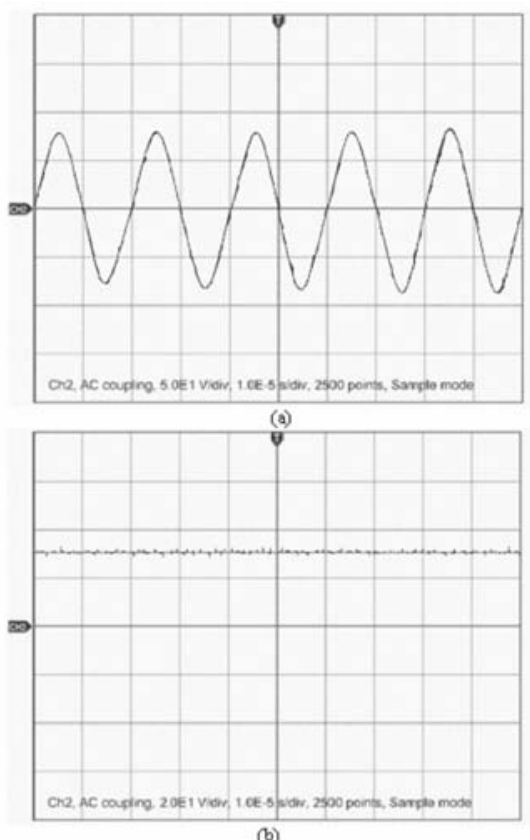

Fig.7 Experimental Results for Series Parallel Resonant Converter at $70 \%$ load with $m=1$ : (a) $V_{c s}$, (b) $V_{0}$ with filter

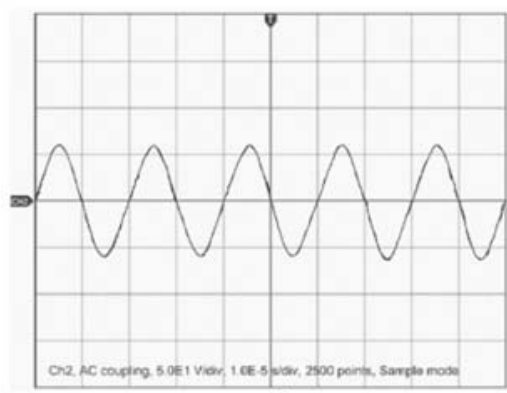

(a)

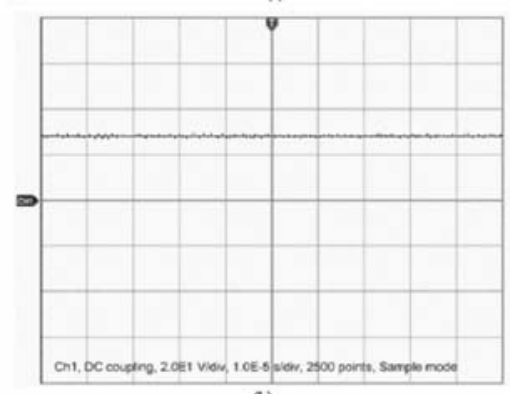

(b)

Fig.8 Experimental Results for Series Parallel Resonant Converter at $40 \%$ load with $m=1$ : (a) $V_{\text {cs }}$, (b) $V_{0}$ with filter

Table.1\&2 gives the Comparison of Results between Calculated and experimental results respectively of Series Parallel Resonant Converter for a input D-C supply Voltage of $30 \mathrm{~V}$ and Switching Frequency of $50 \mathrm{kHz}$.

Table.1 Calculated

\begin{tabular}{|c|c|c|c|c|c|c|c|}
\hline $\begin{array}{c}\text { load } \\
\%\end{array}$ & $\begin{array}{l}\text { series } \\
\text { capacitor } \\
\text { voltage } \\
\text { Vcs(peak) } \\
\text { (volts) }\end{array}$ & $\begin{array}{l}\text { paratllel } \\
\text { capacitor } \\
\text { voltage } \\
\text { Vcpppeaks) } \\
\text { (volts) }\end{array}$ & $\begin{array}{c}\text { Vo(peak) } \\
\text { (without } \\
\text { filter) } \\
\text { (volts) }\end{array}$ & $\begin{array}{r}\text { Wo } \\
\text { (with } \\
\text { filter) } \\
\text { (volts) }\end{array}$ & $\begin{array}{l}\text { speed } \\
\text { (tppm) }\end{array}$ & $\begin{array}{l}\text { ripple } \\
\text { factor } \\
\text { (without } \\
\text { filter) } \\
\%\end{array}$ & $\begin{array}{c}\text { ripple } \\
\text { factor } \\
\text { (with } \\
\text { filter) } \\
\%\end{array}$ \\
\hline 100 & 88.91 & 44.05 & 44.0 & 32.5 & 4000 & 20.47 & 1.04 \\
\hline 90 & 82.83 & 42.93 & 42.9 & 31.6 & 4000 & 20.37 & 1.03 \\
\hline 80 & 73.76 & 40.86 & 40.8 & 30.6 & 4000 & 20.2 & 1.01 \\
\hline 70 & 67.45 & 38.94 & 38.9 & 29.6 & 4000 & 20.14 & 1.00 \\
\hline 60 & 59.04 & 37.33 & 37.3 & 28.8 & 4000 & 18.58 & 0.99 \\
\hline 40 & 50.04 & 34.51 & 34.5 & 27.5 & 4000 & 15.8 & 0.97 \\
\hline
\end{tabular}

Table. 2 experimental

\begin{tabular}{|c|c|c|c|c|c|c|c|}
\hline $\begin{array}{l}\text { lood } \\
\%\end{array}$ & $\begin{array}{l}\text { series } \\
\text { capacitor } \\
\text { roltage } \\
\text { Vces(pedk) } \\
\text { (volts) }\end{array}$ & $\begin{array}{l}\text { pertillel } \\
\text { capacitor } \\
\text { voltage } \\
\text { Vep(peak) } \\
\text { (volts) }\end{array}$ & $\begin{array}{l}\text { Vo(peak) } \\
\text { (without } \\
\text { filtet) } \\
\text { (volts) }\end{array}$ & $\begin{array}{l}\text { Vo } \\
\text { (with } \\
\text { filtet) } \\
\text { (volts) }\end{array}$ & $\begin{array}{c}\text { speed } \\
(\mathrm{ppm})\end{array}$ & $\begin{array}{l}\text { tipple } \\
\text { factor } \\
\text { (without } \\
\text { filtet) } \\
\%\end{array}$ & $\begin{array}{l}\text { ripple } \\
\text { factor } \\
\text { (with } \\
\text { filter) } \\
\%\end{array}$ \\
\hline 100 & 98.6 & 481 & 46.5 & 329 & 4000 & 21.1 & 1.19 \\
\hline 90 & 925 & 468 & 453 & 32.1 & 4000 & 20.9 & 1.18 \\
\hline 80 & 84.4 & 446 & 432 & 313 & 4000 & 20.6 & 1.16 \\
\hline 70 & $\pi .1$ & 425 & 41.1 & 30.4 & 4000 & 20.4 & 1.14 \\
\hline 60 & 67.6 & 41.1 & 397 & 293 & 4000 & 197 & 1.12 \\
\hline 40 & 608 & 383 & 369 & 28.2 & 4000 & 16.8 & 111 \\
\hline
\end{tabular}




\section{CONCLUSION}

Anew high frequency regulation method for a DC-DC converter is presented that permits the implementation of a voltage control strategy Regulation is achieved by varying the conduction angle of the switching devices. The switches are operated under zero current conditions and therefore results in much higher efficiency and reduced voltage stresses. The regulation principle is general and can be implemented in any kind of converter without modifying its operation. Based on the converter analysis, characteristic curves have been obtained and a step by step design procedure of the converter has been given. Results obtained from the prototype verify the feasibility and the advantages of the topology.

\section{REFERENCES}

[1] A.K.S. Bhat and S.B. Dewan, Oct.1987. "Analysis \& Design of a high frequency resonant converter using LCC Type Communtation", IEEE Trans. on Power Electronics Vol.2, pp.291 - 301.

[2] A.K.S. Bhat, Jan.1993. "Analysis \& design of series parallel resonant converter", IEEE Trans. on PE Vol.8, No.1,pp.174-182.

[3] AndrewJ.Foryth, Gillian .A .Ward, StefanV Mollow Nov 2003. "Extendedfundamental frequency analysis of the LCC resonant converter" IEEETrans.onPEVol.8 No.6,pp.12861292.

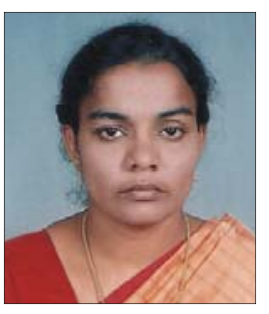

Y.Sukhi received the B.E degree in Electrical and Electronics Engineering from Government College of Engineering, Tirunelveli in 1993, M.E degree in Mechatronics from Anna University, M.I.T.Campus, in 2000 and is currently doing her Ph.D in Sathyabama University. She has 15 years of teaching experience.

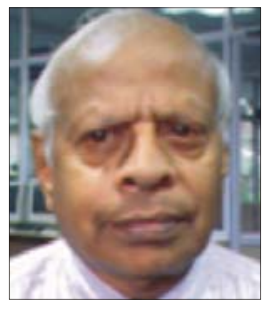

Dr.S.Padmanabhan received the B.E (Honors) degree from University of Madras; M.Tech from I.I.T Bombay; M.E.E from Stevens Tech, USA and Ph.D from I.I.T Kanpur.He has got 30 years of experience in teaching and 10years of experience in industry 